\title{
Design and analysis of the movable solar power system
}

\author{
Lian Zhang ${ }^{1,2}$ and Zijian Chen ${ }^{1, a}$ \\ ${ }^{1}$ School of Electrical and Energy, Tianjin Sino-German University of Applied Sciences, Tianjin, China, \\ http://www.zdtj.cn/ \\ ${ }^{2}$ China Computer-Room Equipment Engineering CO.,LTD, Tianjin, China
}

\begin{abstract}
This paper describes the design of the movable solar power system from the appearance structure, photovoltaic(PV) power generationfromthe two aspects. The data of the system can be monitored and output for testing and analysis. The system can generate $691 \mathrm{kWh}$ of electricity per year.The system is equipped with rolling wheels and the removable simulated light source, which can be used for the outdoor application of daily life in backward areas or lonely islands and the indoor teaching and training of energyspecialty.The system can be widely used even without the electric source.
\end{abstract}

Keywords: movable; system design; solar power system; PV power generation

\section{Introduction}

The technology of solar power system is early invented, and has been greatly developed and popularized in the world. Recently, the research of solar power system is focused on the PVcell [1], PV module [2], system design [3-4] and so on. Considering these questions, this paper design the movable solar power system, the specific contents are as follows.

\section{System design}

The design of the movable solar power systemincludes the appearance structure and the PV power generation.

\subsection{Appearance structure}

The components of the appearance structure of the system arebased on figure 1 and table 1.The figure 1 is the front view, rear view andside view of the appearancestructure.The PV modulesare mounted on the supporting platform. The supporting platform is embedded inmovable frame, and can be adjusted for change the angle [5] of the PV modules by the adjustment bracket. The angle can be measured by the protractor. Batteriesare fixed in the movable frame. The rolling wheels are installed at the bottom of the movable frame. When the PV modules work and the sunirradiates on the PV cells, the rays canbe transformed into electric energy according to PV effect.The function of the simulated light source is to simulate the sun. In the actual environment, the simulated light source can be

\footnotetext{
${ }^{a}$ Corresponding author : 375352039@qq.com
} 
removed.Similarly, thesystem has the ability of movingby rolling wheels, which greatly improves the environmental adaptability.
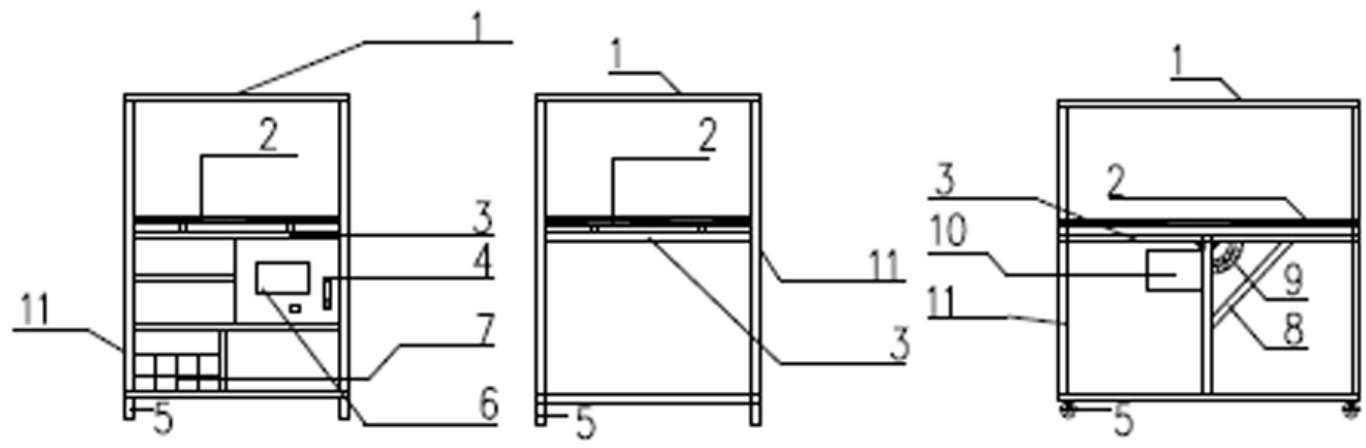

Figure 1. The frontview, rear view andside view of the appearancestructure

Table 1. The visible components of the appearance structureaccording to the figure 1

\begin{tabular}{cccc}
\hline $\begin{array}{c}\text { Labels according } \\
\text { to the figure 1 }\end{array}$ & Components & $\begin{array}{c}\text { Labels according to } \\
\text { the figure 1 }\end{array}$ & Components \\
\hline 1 & $\begin{array}{c}\text { Simulated light } \\
\text { source } \\
\text { PV modules }\end{array}$ & 7 & Batteries \\
2 & $\begin{array}{c}\text { Supporting } \\
\text { platform }\end{array}$ & 9 & $\begin{array}{c}\text { Adjustment } \\
\text { bracket } \\
\text { Protractor }\end{array}$ \\
4 & $\begin{array}{c}\text { Control cabinet } \\
\text { Rolling wheels } \\
\text { Touch screen }\end{array}$ & 10 & $\begin{array}{c}\text { Switch box } \\
\text { Movable frame }\end{array}$ \\
6 & & 11 & . \\
\hline
\end{tabular}

\subsection{PV power generation}

Two PV modules are connected in parallel and charging the batteries [6]. Four batteries connected in series and then connected in parallel. Therefore, the voltage of these PV modules and the voltage of these batteries are matched. When the power supply of 24V DC is needed, these batteries output electric energy directly for these loads. If $220 \mathrm{~V}$ AC is needed, the electric energy of $24 \mathrm{~V}$ DC can be invert into $220 \mathrm{~V} \mathrm{AC}$ by the inverter [7].

$24 \mathrm{~V}$ DC can be supplied for the I/O control board, the touch screen, the electric relays and two DC current sensors.

The I/O control boardcontrols the system, including CPU, ports, interface, communication chips, and all kinds of conversion chips. The first DC current sensor [8] collects the output current of these PV modules, and thentransmits the data of the current to the analogue input(AI) ports of the I/Oboard. The data of the voltage of thesebatteries aretransmitted to the AI ports of the I/Oboard. The second DC current sensor collects the current of the power supply for these loads, and thentransmits the data of the current to the AI ports of the I/Oboard.The data of the touch screen are communicated to the COM interface of the I/O board. The I/O board outputs the signals through the digital output (DO) ports to the relays. The first and second relays control the power supply of these PV modules. The third relay controls the power supply of the loads. The I/O board can control the relevant output signals according to the obtained data automatically. Above working principle are based on figure 2 and table 2. It is worth mentioning that only the removablelight source depends on the $220 \mathrm{~V} \mathrm{AC}$ power supply, but other components only depend on the 24V DC power supply. So the system can be self-sufficient without the electric source. 
AEST2016

Table 2. The components of the heat circulating according to the figure 2

\begin{tabular}{cccc}
\hline $\begin{array}{c}\text { Labels } \\
\text { according to } \\
\text { the figure 2 }\end{array}$ & Components & $\begin{array}{c}\text { Labels according to the } \\
\text { figure 2 }\end{array}$ & $\begin{array}{c}\text { Compone } \\
\text { nts }\end{array}$ \\
\hline $\mathrm{D}$ & Diodes & FU & $\begin{array}{c}\text { Fuses } \\
\text { Air switches }\end{array}$ \\
QF & HMI & $\begin{array}{c}\text { Touch } \\
\text { screen }\end{array}$ \\
K & Electric relays & SH & On-off \\
GB & Batteries & RL & Loads \\
BHBM & DC current & $24+, 0-$ & 24V DC \\
& sensors & & \\
UI & Inverter & & \\
\hline
\end{tabular}

\section{System testing and analysis}

The monitoring and controlling of the system relies on the touch screen [9], which can communicate with the I/O board. Users can monitor the automatic mode, and also can control the manual mode. Meanwhile the real-time data and historical data such as voltage, current, power and electric energy of the system can be collected and downloaded. 


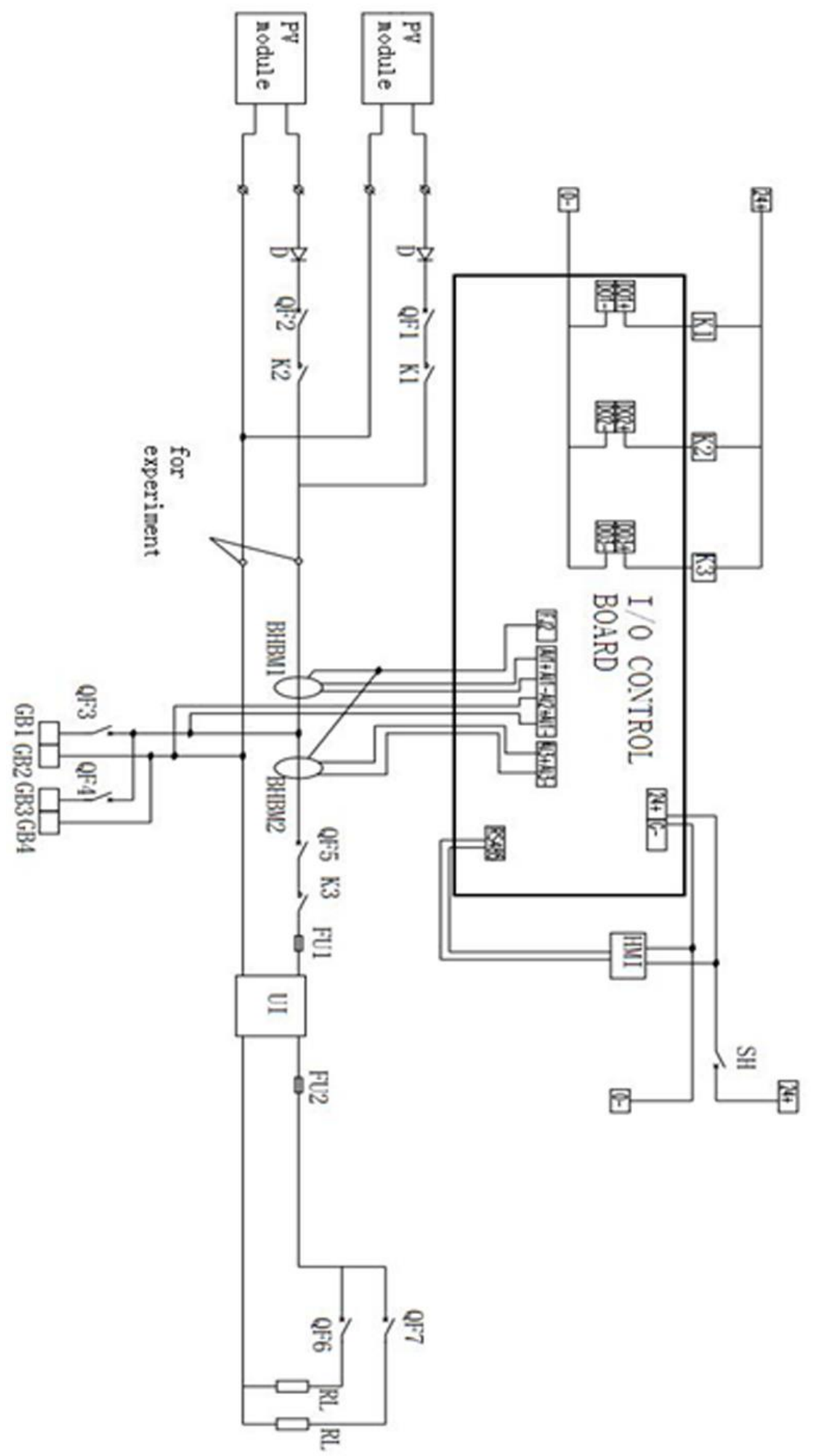

Figure 2. The schematic of the PV power generation 
The maximum power point [10] of the system can be found according to the V-I characteristic curve [11] and the P-Vcurve. Figure 3 is the experimentaldata of the open circuit voltage, the shortcircuit current, the V-I characteristic curve and the P-Vcurve of the system.

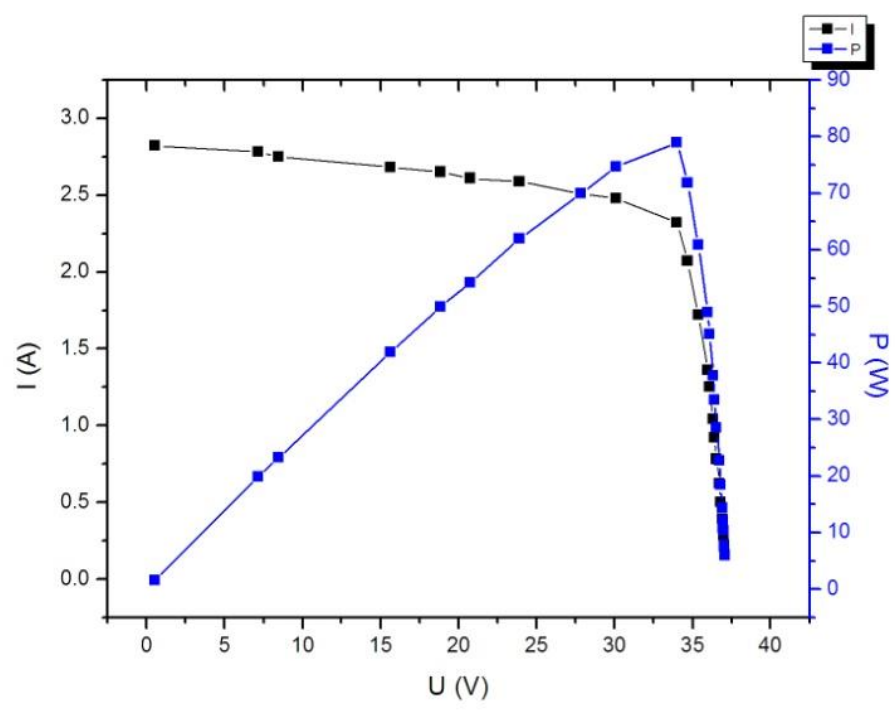

Figure 3. The open circuit voltage, the short-circuit current, the V-I characteristic curve and the P-Vcurve of the system

The fill factor of the system can be calculated according to Eq. (1):

$$
F F=\frac{P_{M A X}}{U_{o c} \times I_{s c}}
$$

Where:

$\mathrm{FF}=$ The fill factor of the system, kWh;

$\mathrm{P}_{\mathrm{MAX}}=$ The maximum power of the system, $\mathrm{kWh}$;

$\mathrm{U}_{\mathrm{OC}}=$ The open circuit voltage of the system, $\mathrm{V}$;

$\mathrm{I}_{\mathrm{SC}}=$ The short-circuit current of the system, A.

The electric energy generated by the system can be calculated. The systemcan generate $691 \mathrm{kWh}$ of electricity per year.

\section{Conclusion}

The main features of this system are as follows.

(i) The system is equipped with rolling wheels and the removable simulated light source, which can be used for the outdoor application of daily life in backward areas or lonely islands and the indoor teaching and training of energy specialty.

(ii) The system has the function of data collectionandenergyconsumptionanalysis. The system can generate $691 \mathrm{kWh}$ of electricity per year.

(iii) The system can be widely used even without the electric source.

\section{Acknowledgments}

This work was supported by the Science Fund of Tianjin Urban and Rural Construction Commission (Grant No. 2014-34) and Tianjin Higher Education Science and Technology Fund Planning Project (Project No. 20140426). 


\section{References}

1. S. Vergura and G. Acciani, 3-D PV-cell model by means of FEM,International Conference on Clean Electrical Power, 35-40(2009)

2. Z.P. Xiong and T.M. Walsh, PV module durability testing under high voltage biased dampheat conditions, Energy Procedia, 384-389,8(2011)

3. L.Zhang and Y.F.Zhang, Research on Energy Saving Potential for Dedicated Ventilation Systems Based on Heat Recovery Technology. Energies, 4261-4280, 7,(2014)

4. L.Zhang and Y.F.Zhang, Research on Heat Recovery Technology for Reducing the Energy Consumption of Dedicated Ventilation Systems: An Application to the Operating Model of a Laboratory, Energies, 24,9,(2016)

5. Y.S. Khoo and A. Nobre,Optimal Orientation and Tilt Angle forMaximizing in-Plane Solar Irradiationfor PV Applications in Singapore, IEEE JOURNAL OF PHOTOVOLTAICS, Vol. 4, 2,3(2014)

6. S.K.Nandi and H.R.Ghosh, Prospect of wind-PV-battery hybrid power system as an alternative to grid extension in Bangladesh, Energy, 3040-3047,35 (2010)

7. G.Velasco and R.Piqué, Power sizing factor design of central inverter PVgrid-connected systems: a simulation approach, International Power Electronics \& Motion Control Conference, 32-36, S9(2010)

8. W.P.Taylor and M.C.Doogue, Integrated current sensor, U. S. Patent, 8,080,994B2, 2011-12-20

9. R.B.Zhou,Dry Powder Automatic Configuration System Based on PLC and Touch Screen, Automation Application, 04,(2014)

10. F.R.Liu and S.X.Duan,A Variable Step Size INC MPPTMethod for PV Systems, IEEE TRANSACTIONS ON INDUSTRIAL ELECTRONICS, Vol. 55, 7, 7(2008)

11. E. D. Aranda and J. A. Gomez Galan, Measuring the I-V curve of PV generator, IEEE Industrial Electronics Magazine,4-14, 3, 3(2009) 